\title{
Spontaneous pneumothorax and tuberculosis: long-term follow-up
}

\author{
J.L. Freixinet*, J.A. Caminero\#, J. Marchenaף, P.M. Rodríguez*, \\ J.A. Casimiro" and M. Hussein*
}

ABSTRACT: Though spontaneous pneumothorax (SP) is a well-known complication of pulmonary tuberculosis (TB), there are very few reports addressing this topic. For this reason, we retrospectively analysed the experience of SP in patients diagnosed with TB in our hospital between 1989 and 2010.

Out of 872 patients treated for SP during this period, $47(5.4 \%)$ had TB antecedents, 21 with active TB ( $0.95 \%$ of the 2,089 TB cases diagnosed during this period) and 26 with residual inactive TB. 46 cases were treated with pleural drainage (PD): 40 (85\%) with only one PD, two with two, and four with three. The mean \pm SD length of PD treatment was $12.9 \pm 11.3$ days. In 11 (23\%) cases, a relapse of SP occurred, with no statistical relationship between the different studied variables. In $13(28 \%)$ cases, it became necessary to carry out a resection (atypical segmentectomy in all cases) for persistent air leaks with PD. Survival statistics were unfavourable only in elderly patients and those infected with HIV.

We conclude that the treatment of SP secondary to TB with PD is usually a sound response, with a good general prognosis and a low percentage of cases that require another PD and surgical treatment.

KEYWORDS: Pleural drainage, pneumothorax, pulmonary tuberculosis, secondary spontaneous pneumothorax, surgical treatment

pontaneous pneumothorax (SP) is defined as the sudden presence of air in the pleural cavity without apparent external cause. The majority of cases can be classified as primary SP, ocurring in the young without associated pulmonary or general disease. The production mechanism of primary SP is the rupture of some subpleural pulmonary alterations known as blebs [1]. Secondary SP (SSP) is associated with clinical or radiological evidence of significant lung disease, most frequently a consequence of chronic obstructive pulmonary disease (COPD). Pulmonary tuberculosis (TB) has been repeatedly described as a frequent cause of SSP [2-6], with a very variable presentation frequency according to the few authors that have studied this matter. Over the past few decades, a clearly growing incidence of SSP caused by TB has been described [4]. The frequency with which SSP can complicate the course of TB has also been little studied, with figures ranging from 0.6 to $1.4 \%$ [5]. These figures, although appearing to be very low, can be supremely important if we keep in mind the 9.5 million new cases that the World Health Organization reports are produced in the world every year [7]. $80 \%$ of these cases occur in developing countries. In spite of the fact that TB is a frequent cause of SSP, very few series, with very few patients, have been reported. Therefore, the frequency of presentation, the clinical and therapeutic management, and the prognosis of these patients have been poorly studied. There is very little contrasting experience with this type of SSP. With the aim of reviewing our experience and shedding some light on these matters, we present our studies of SSP and TB over the past 21 yrs.

\section{MATERIALS AND METHODS}

The Dr Negrín General Hospital (Las Palmas, Spain) serves a population of $\sim 500,000$ people, corresponding to the northern area of the island of Gran Canaria. There is one thoracic surgery unit in this area, to which all cases of SP are referred. The average incidence of $\mathrm{TB}$ on the island of Gran Canaria was 32.2 cases per 100,000 inhabitants in 1988 and 23 cases per 100,000 inhabitants in 2009 [8].

The present study is observational, retrospective and longitudinal, analysing data corresponding to clinical reports of all patients with SSP and TB treated in our hospital between January 1, 1989 and December 31, 2009. The following data were
AFFILIATIONS

*Thoracic Surgery Service,

\#Pneumology Service, and

-General Surgery Service, University Hospital of Gran Canaria Dr Negrín,

Las Palmas, Spain.

CORRESPONDENCE

J.L. Freixinet

Thoracic Surgery Service

University Hospital Dr. Negrín

Barranco de la Ballena s/n

35020 Las Palmas de Gran Canaria

Spain

E-mail: jfregil@

gobiernodecanararias.org

Received:

Aug 112010

Accepted after revision:

Oct 032010

First published online:

Oct 142010

European Respiratory Journal

Print ISSN 0903-1936

Online ISSN 1399-3003 
collected from the medical records: age, sex, domicile, comorbidity and past medical history (smoking, alcoholism, drug addiction, social indigence, functional criteria of COPD, previous respiratory infections, previous TB and other pneumological antecedents), clinical data (dyspnoea, pleuritic pain, fever, cough, expectoration, diagnosis of active TB, bronchopleural fistula and whether the patient was in treatment with anti-TB drugs), diagnostic method for pneumothorax (radiography and computed tomography (CT) scan), its location and radiological characteristics (presence of pulmonary infiltrates, pulmonary atelectases, caverns, bronchiectasis, destroyed lung, granulomas, pachypleuritis, calcium plaques, pleural effusion and mediastinal adenopathies), data related to pleural drainage (PD) (duration in days and recurrence of SSP needing PD again), necessity for surgery and type of surgery performed, hospital stay, number of admittances, complications and perioperative mortality (exitus during the same admittance), and long-term survival. Long-term survival was considered to be length of the period between the performance of the pleural drainage and death, or the date of the last follow-up observation before the analysis if the subject was still alive. For the follow-up, the hospital's database was used. The variables considered as end-points were recurrence of SSP and long-term survival after having suffered a pneumothorax.

Diagnosis of SSP was always confirmed through radiological studies, either conventional thoracic radiography or CT. All radiological examinations were evaluated by an independent radiologist.

In all but one case, PD was performed. The procedure was carried out under local anaesthesia, inserting a 28-French drainage tube in the anterior axillary line, fifth intercostal space. Surgical intervention (thoracotomy or video thoracoscopy) was indicated in the presence of air leaks lasting for $>10$ days and when there was a recurrence of SSP. For this indication, the general performance status of the patient was taken into account as well as pulmonary parenchymal involvement, and the presence of pleural sequelae. In all cases possible, a test of respiratory function was performed. If there was any suspicion of endobronchial pathology, bronchoscopy was indicated.

\section{Statistical analysis}

Analyses were performed using SPSS version 14.0 (SPSS Inc., Chicago, IL, USA). The placement of PD was considered as the initial date of the study. A descriptive analysis of the sample was performed, estimating the frequency and the corresponding percentages in the case of categorical variables and the mean \pm SD. Afterwards, possible relationships among descriptor variables were studied along with those considered endpoints. In the case of categorical variables, the Chi-squared test was used and, in cases where this did not meet the conditions of the application, Fisher's exact test was performed. As for numerical variables, in order to compare measurements, unpaired t-tests were applied.

Survival curves were calculated according to the Kaplan-Meier method. Differences in survival were analysed with the log-rank test and the hazard ratio (HR) was estimated. The relationship between the numeric variable age and survival was estimated using Cox regression. In all cases, a p-value $<0.05$ was considered significant.

\section{RESULTS}

During the study period, a total of 872 patients with SP were treated in our hospital, 47 (5.4\%) of whom had SSP secondary to TB. Also during this period, 2,089 cases of active TB were treated. Of the 47 cases with SSP secondary to TB, 21 presented with active TB at the moment of producing SSP (positive culture for Mycobacterium tuberculosis) and 26 with inactive residual TB. This supposes that $0.95 \%$ of active TB cases had this complication. In the other 26 cases, there were clinical data and radiographic evidence to support inactive $\mathrm{TB}$, all with extensive residual lesions considered to be the cause of SSP. Of the 47 patients studied, $43(91.5 \%)$ were males and four $(8.5 \%)$ were females $(\mathrm{p}<0.001)$. The mean $\pm \mathrm{SD}$ age was $46.6 \pm 15.6$ (range 23-92) yrs.

Personal antecedents are shown in table 1. Of the total sample, $14(29.8 \%)$ patients had some type of pulmonary antecedent, with 11 standing out as meeting the criteria for COPD and two having more than one antecedent. As stated, $21(44.7 \%)$ patients had a diagnosis of active TB and were undergoing a complete anti-TB drug therapeutic regimen at the time the SSP occurred.

The clinical manifestations presented by the patients are shown in table 2, with dyspnoea (63.8\%) standing out, followed by expectoration $(55.3 \%)$, cough $(48.9 \%)$ and pleuritic pain $(51.1 \%)$. Almost half of the patients with SSP secondary to TB presented no thoracic pain.

Radiological diagnosis was performed by simple thoracic radiography in all patients, and confirmed by $\mathrm{CT}$ in the other $15(32 \%)$. In $26(55.3 \%)$ cases, SSP was found on the right side, and in $19(40.4 \%)$ cases it was found on the left. In two $(4.3 \%)$ cases, SSP was bilateral. Apart from the SSP, all patients had radiological alterations, bilateral in $40(85.1 \%)$ patients, limited to the right side in five $(10.6 \%)$ and to the left in two $(4.2 \%)$. The observed radiological alterations accompanying SSP are shown in table 2 . It is notable that 38 patients $(80.8 \%)$ had some form of destroyed lung and that $33(70.2 \%)$ presented infiltrates.

With regard to PD as a treatment for SSP, 40 (85\%) patients needed one PD, two (4\%) needed two, and four (9\%) needed three. A decision to wait was made in only one patient, and the evolution of their SSP was favourable during their stay. The mean \pm SD stay for PD was $12.9 \pm 11.3$ (range 4-58) days. There were no complications from this technique.

In $11(23 \%)$ patients, SSP recurred. Table 2 shows a univariate analysis that was performed in order to study the possible causes of the recurrence, without finding any statistical relationship among clinical variables, analysed radiography and this recurrence. Therefore, not even factors such as suffering active TB, fibrotic TB (radiological infiltrates) or having radiological patterns of destroyed lung were more associated with this recurrence. The treatment for these recurrences was to perform another PD in eight $(17 \%)$ cases, one of them contralateral, and three patients needed surgery.

An atypical pulmonary segmentectomy was performed in 13 $(28 \%)$ patients for persistent air leakage after PD $(n=10)$ and 


\begin{tabular}{|c|c|c|c|c|}
\hline \multirow[t]{2}{*}{ Variable } & \multirow[t]{2}{*}{ Cases n } & \multicolumn{2}{|c|}{ Recurrence of pneumothorax } & \multirow[t]{2}{*}{ p-value } \\
\hline & & Yes & No & \\
\hline All patients & 47 & $11(23.4)$ & $36(76.6)$ & \\
\hline \multicolumn{5}{|l|}{ Sex } \\
\hline Male & 43 & $10(90.9)$ & $33(91.7)$ & 0.670 \\
\hline Female & 4 & $1(9.1)$ & $3(8.3)$ & \\
\hline Age yrs & 47 & $42.8 \pm 14.9$ & $47.7 \pm 15.8$ & 0.717 \\
\hline i.v. drug abuse & 12 & $2(18.2)$ & $10(27.8)$ & 0.703 \\
\hline Alcoholism & 19 & $5(45.5)$ & $14(38.9)$ & 0.737 \\
\hline Smoker & 36 & $7(63.6)$ & 29 (80.6) & 0.256 \\
\hline Social indigence & 7 & $3(27.3)$ & $4(11.1)$ & 0.330 \\
\hline Pneumonia & 5 & $1(9.1)$ & $4(11.1)$ & 0.668 \\
\hline COPD & 11 & $1(9.1)$ & $10(27.8)$ & 0.416 \\
\hline HBV & 1 & $0(0.0)$ & $1(2.8)$ & 0.766 \\
\hline HCV & 4 & $1(9.1)$ & $3(8.3)$ & 0.670 \\
\hline HIV & 3 & $1(9.1)$ & $2(5.6)$ & 0.560 \\
\hline $\begin{array}{l}\text { Mediastinal } \\
\text { adenopathies }\end{array}$ & 5 & $2(18.2)$ & $3(8.3)$ & 0.332 \\
\hline $\begin{array}{l}\text { Pulmonary } \\
\text { atelectasis }\end{array}$ & 13 & $4(36.4)$ & $9(25.0)$ & 0.467 \\
\hline Bronchiectasis & 17 & $3(27.3)$ & 14 (38.9) & 0.373 \\
\hline Pleural effusion & 6 & $0(0)$ & $6(16.7)$ & 0.181 \\
\hline Caverns & 21 & $6(54.5)$ & $15(41.7)$ & 0.505 \\
\hline Active TB & 21 & $5(45.5)$ & $16(44.4)$ & 0.610 \\
\hline $\begin{array}{c}\text { Incomplete TB } \\
\text { treatment }\end{array}$ & 26 & $6(54.5)$ & $20(57.1)$ & 0.575 \\
\hline $\begin{array}{l}\text { Pulmonary } \\
\text { destruction }\end{array}$ & 25 & $6(54.5)$ & $19(52.8)$ & 0.857 \\
\hline $\begin{array}{l}\text { Pulmonary } \\
\text { infiltrates }\end{array}$ & 33 & $9(81.8)$ & $24(66.7)$ & 0.464 \\
\hline Pleural thickening & 26 & $5(45.5)$ & $21(58.3)$ & 0.505 \\
\hline $\begin{array}{l}\text { Bronchopleural } \\
\text { fistula }\end{array}$ & 10 & $3(27.3)$ & $7(19.4)$ & 0.430 \\
\hline Granulomas & 14 & $5(45.5)$ & $9(25.0)$ & 0.177 \\
\hline Pachypleuritis & 24 & $4(36.4)$ & $20(57.1)$ & 0.229 \\
\hline Calcium plaques & 10 & $4(36.4)$ & $6(16.7)$ & 0.164 \\
\hline Surgery & 13 & $4(36.4)$ & $9(25.0)$ & 0.353 \\
\hline
\end{tabular}

Data are presented as $\mathrm{n}(\%)$ or mean $\pm \mathrm{SD}$, unless otherwise stated. COPD: chronic obstructive pulmonary disease; HBV: hepatitis B virus; HCV: hepatitis C virus. ${ }^{\#}$ : using the Chi-squared test.

relapses $(n=3)$. Operations were carried out by axillary thoracotomy in five cases, lateral thoracotomy in seven and videothoracoscopy in one. There were five $(38.4 \%)$ postoperative complications: persistent air leaks for $>5$ days in three cases, pneumonia in one case and surgical wound infection in one. There was no post-operative mortality. The mean \pm SD hospital length of stay was $17.09 \pm 17.04$ (range 4-73) days. On three occasions, Heimlich valves were placed for persistent air leaks (two post-operatively). Intrahospital mortality was $4 \%$ (two patients, in both cases due to severe pneumonia, not SSP).

\begin{tabular}{lc} 
TABLE 2 & $\begin{array}{c}\text { Descriptive analysis: clinical characteristics and } \\
\text { radiological findings of the sample studied }\end{array}$ \\
Variable & Cases \\
\hline Clinical characteristics & \\
Active TB & $21(44.7)$ \\
Enolism & $19(40.4)$ \\
Drug addiction & $12(25.5)$ \\
COPD & $11(23.4)$ \\
Social indigence & $7(14.9)$ \\
Pneumonia & $5(10.6)$ \\
HCV & $4(8.5)$ \\
HIV & $3(6.4)$ \\
HBV & $1(2.1)$ \\
Dyspnoea & $30(63.8)$ \\
Expectoration & $26(55.3)$ \\
Cough & $23(48.9)$ \\
Chest pain & $24(51.1)$ \\
Fever & $20(42.6)$ \\
Bronchopleural fistula & $10(21.7)$ \\
Radiological findings & \\
Infiltrates & $33(70.2)$ \\
Pleural thickening & $26(55.3)$ \\
Pulmonary destruction & $25(53.2)$ \\
Caverns & $21(44.7)$ \\
Bronchiectasis & $17(36)$ \\
Granulomas & $14(29.8)$ \\
Pulmonary atelectasis & $13(27.7)$ \\
Pleural calcifications & $10(21.3)$ \\
Pleural effusion & $6(12.8)$ \\
Mediastinal adenopathies & $5(10.6)$ \\
\hline & \\
& \\
\hline
\end{tabular}

Data are presented as $n(\%) . n=47$. TB: tuberculosis; COPD: chronic obstructive pulmonary disease; $\mathrm{HCV}$ : hepatitis $\mathrm{C}$ virus; HBV: hepatitis $\mathrm{B}$ virus.

At the close of the study, $14(30 \%)$ patients had died and 31 $(66 \%)$ were still alive. Two patients were lost to follow-up. Cause of death was respiratory insufficiency in eight cases, pneumonia in three cases and liver insufficiency in two cases. The cause of death could not be determined for one patient. Table 3 shows a univariate analysis of the multiple factors analysed in relation to long-term survival using the log-rank test. Of the different variables analysed, the only predictors of poor prognosis were the patient's age (HR 1.063, 95\% CI 1.026$1.101 ; \mathrm{p}<0.001$ ) (the older the patient, the worse the prognosis) and HIV infection (HR 6.336, 95\% CI 1.301-30.867; $\mathrm{p}=0.009$ ).

The curve of long-term survival for the studied series is shown in figure 1. The average survival was $\sim 11$ yrs (135 months, $95 \%$ CI 64.7-205.1 months). The probability of survival at 1, 3, 5 and 10 yrs was 95.6, 84.8, 81.5 and 56.8\%, respectively.

\section{DISCUSSION}

The presence of SP during the evolution of active TB is a wellknown situation. However, it has not been sufficiently studied to date. Previous studies have shown a 0.6 [2] to $1.4 \%$ [4] possibility of this occurring, which is very similar to the $0.95 \%$ found in the present study. It would seem, therefore, that we could estimate $\sim 1 \%$ of patients with active TB might present 


\begin{tabular}{|c|c|c|c|c|c|}
\hline & Cases $n$ & Events & Censored & $\mathrm{HR}(95 \% \mathrm{Cl})$ & p-value \\
\hline Total & 46 & $14(30)$ & $32(70)$ & & \\
\hline $\mathrm{Age}^{+}$yrs & & $58.5 \pm 17.1$ & $41.3 \pm 41.1$ & $1.06(1.03-1.10)$ & 0.001 \\
\hline \multicolumn{6}{|l|}{ Sex } \\
\hline Male & 42 & 14 (33.3) & $28(66.7)$ & $0.04(0.00-21.12)$ & 0.102 \\
\hline Female & 4 & $0(0.0)$ & $4(100)$ & & \\
\hline \multicolumn{6}{|c|}{ Drug addiction } \\
\hline Yes & 12 & $1(8.3)$ & $11(91.7)$ & $4.95(0.65-37.96)$ & 0.088 \\
\hline No & 34 & $13(38)$ & $21(61.8)$ & & \\
\hline \multicolumn{6}{|l|}{ Alcoholism } \\
\hline Yes & 19 & $8(42.1)$ & $11(57.9)$ & $0.586(0.20-1.70)$ & 0.320 \\
\hline No & 27 & $6(22.2)$ & $21(77.8)$ & & \\
\hline \multicolumn{6}{|l|}{ Smoker } \\
\hline Yes & 36 & $13(36.1)$ & $23(63.9)$ & $0.23(0.03-1.73)$ & 0.117 \\
\hline No & 10 & $1(10.0)$ & $9(90.0)$ & & \\
\hline \multicolumn{6}{|c|}{ Social indigence } \\
\hline Yes & 7 & $3(43.0)$ & $4(57.0)$ & $0.27(0.07-1.11)$ & 0.052 \\
\hline No & 39 & 11 (28.2) & $28(71.8)$ & & \\
\hline \multicolumn{6}{|l|}{ Pneumonia } \\
\hline Yes & 5 & $2(30.0)$ & $3(60.0)$ & $0.48(0.11-2.19)$ & 0.335 \\
\hline No & 41 & 12 (29.3) & $29(70.7)$ & & \\
\hline \multicolumn{6}{|l|}{ COPD } \\
\hline Yes & 11 & $6(54.5)$ & $5(45.5)$ & $0.37(0.12-1.11)$ & 0.064 \\
\hline No & 35 & $8(22.9)$ & $27(77.1)$ & & \\
\hline \multicolumn{6}{|l|}{ HBV } \\
\hline Yes & 1 & $0(0.0)$ & $1(100)$ & 20.76 (NC) & 0.881 \\
\hline No & 45 & $14(31.1)$ & $31(68.9)$ & & \\
\hline \multicolumn{6}{|l|}{ HVC } \\
\hline Yes & 4 & $1(25.0)$ & $3(75.0)$ & $0.526(0.07-4.24)$ & 0.540 \\
\hline No & 42 & $13(31.0)$ & $29(69.0)$ & & \\
\hline \multicolumn{6}{|l|}{ HIV } \\
\hline Yes & 3 & $2(66.7)$ & $1(33.3)$ & $6.34(1.30-30.87)$ & 0.009 \\
\hline No & 43 & $12(27.9)$ & $31(72.1)$ & & \\
\hline \multicolumn{6}{|c|}{$\begin{array}{l}\text { Mediastinal } \\
\text { adenopathies }\end{array}$} \\
\hline Yes & 5 & $0(0)$ & $5(100.0)$ & $23.16(0.00-2186)$ & 0.409 \\
\hline No & 41 & $14(34.1)$ & 27 (65.9) & & \\
\hline \multicolumn{6}{|c|}{$\begin{array}{l}\text { Pulmonary } \\
\text { atelectasis }\end{array}$} \\
\hline Yes & 13 & $2(15.4)$ & $11(84.6)$ & $1.77(0.39-7.95)$ & 0.453 \\
\hline No & 33 & $12(36.4)$ & $12(63.6)$ & & \\
\hline \multicolumn{6}{|c|}{$\begin{array}{l}\text { Pumonary } \\
\text { bronchiectasis }\end{array}$} \\
\hline Yes & 17 & $6(35.3)$ & $11(64.7)$ & $0.59(0.20-1.78)$ & 0.347 \\
\hline No & 29 & $8(27.6)$ & $21(72.4)$ & & \\
\hline \multicolumn{6}{|l|}{ Caverns } \\
\hline Yes & 21 & $6(28.6)$ & $15(71.4)$ & $0.97(0.33-2.84)$ & 0.957 \\
\hline No & 25 & $8(32.0)$ & $17(68.0)$ & & \\
\hline \multicolumn{6}{|c|}{ Pleural effusion } \\
\hline Yes & 6 & $2(33.3)$ & $4(66.7)$ & $0.62(0.13-2.91)$ & 0.542 \\
\hline No & 40 & $12(30.0)$ & $28(70.0)$ & & \\
\hline \multicolumn{6}{|c|}{$\begin{array}{l}\text { Pulmonary } \\
\text { destruction }\end{array}$} \\
\hline Yes & 25 & $9(36.0)$ & $16(64.0)$ & $0.34(0.10-1.12)$ & 0.063 \\
\hline No & 21 & $5(23.8)$ & $16(76.2)$ & & \\
\hline
\end{tabular}

\section{TABLE 3 Continued}

Cases $^{*}$ n Events Censored HR $(95 \% \mathrm{Cl})$ p-value

\begin{tabular}{|c|c|c|c|c|c|}
\hline \multicolumn{6}{|c|}{ Pleural thickening } \\
\hline Yes & 25 & $8(32.0)$ & $17(68.0)$ & $0.46(0.15-1.48)$ & 0.185 \\
\hline No & 21 & $6(28.6)$ & $15(71.4)$ & & \\
\hline \multicolumn{6}{|c|}{$\begin{array}{l}\text { Bronchopleural } \\
\text { fistula }\end{array}$} \\
\hline Yes & 10 & $1(10.0)$ & $9(90.0)$ & $3.26(0.43-24.98)$ & 0.228 \\
\hline No & 36 & $13(36.1)$ & 23 (63.9) & & \\
\hline \multicolumn{6}{|l|}{ Granulomas } \\
\hline Yes & 14 & $5(35.7)$ & $9(64.3)$ & $0.94(0.31-2.83)$ & 0.905 \\
\hline No & 32 & $9(28.1)$ & $23(71.9)$ & & \\
\hline \multicolumn{6}{|l|}{$\begin{array}{l}\text { Pulmonary } \\
\text { infiltrates }\end{array}$} \\
\hline Yes & 32 & $10(31.2)$ & 22 (68.8) & $1.05(0.33-3.38)$ & 0.936 \\
\hline No & 14 & $4(28.6)$ & $10(71.4)$ & & \\
\hline \multicolumn{6}{|c|}{ Pachypleuritis } \\
\hline Yes & 24 & $7(29.2)$ & $17(70.8)$ & $0.67(0.22-2.05)$ & 0.475 \\
\hline No & 22 & $7(31.8)$ & 15 (68.2) & & \\
\hline \multicolumn{6}{|c|}{ Calcium plaques } \\
\hline Yes & 10 & $3(30.0)$ & $7(70.0)$ & $0.85(0.23-3.10)$ & 0.806 \\
\hline No & 36 & 11 (30.6) & $25(69.4)$ & & \\
\hline \multicolumn{6}{|l|}{ TB active } \\
\hline Yes & 21 & $5(23.8)$ & 16 (76.2) & $1.04(0.34-3.15)$ & 0.951 \\
\hline No & 25 & $9(36.0)$ & $16(64.0)$ & & \\
\hline \multicolumn{6}{|c|}{ Treatment of TB } \\
\hline Complete & 20 & $4(20.0)$ & $16(80.0)$ & $1.19(0.36-3.94)$ & 0.772 \\
\hline Incomplete & 25 & $9(36.0)$ & $16(64.0)$ & & \\
\hline \multicolumn{6}{|l|}{ Surgery } \\
\hline Yes & 13 & $1(7.7)$ & $12(92.3)$ & $4.38(0.57-35.60$ & 0.120 \\
\hline No & 33 & $13(39.4)$ & $20(60.6)$ & & \\
\hline \multicolumn{6}{|l|}{ Recurrence } \\
\hline Yes & 11 & $3(27.3)$ & 8 (72.7) & $0.83(0.23-3.01)$ & 0.782 \\
\hline No & 35 & $11(31.4)$ & $24(68.6)$ & & \\
\hline
\end{tabular}

Data are presented as $n(\%)$ or mean \pm SD, unless otherwise stated. Event: death during the follow-up period; censored: number of patients who were still alive at the end of the last interval of the follow-up. HR: hazard ratio; COPD: chronic obstructive pulmonary disease; HBV: hepatitis B virus; HCV: hepatitis C virus; NC: not computable. ${ }^{\#}$ : using the log-rank test, with the exception of age. $\because: \mathrm{n}=46$, as one patient was lost during follow-up. ${ }^{+}$: estimated by Cox regression.

this problem [6], a fact that should be taken into account by all national programmes for TB control. It is very likely that many of them go unnoticed, especially in low-income countries, where $>85 \%$ of the TB patients in the world are living.

It is surprising that SSP as a complication of TB, which has been so accepted for so long, has been the topic of so few publications. There are also very few reports analysing the place that SSP secondary to TB occupies in the total gamut of SSP occurrences. Moreover, the few works that have analysed the relationship between TB and SSP are sometimes conflicting. WILDER et al. [6], in 1962, stated that 78\% of SSPs studied were due to $\mathrm{TB}$, which supposes that $1.4 \%$ of patients with TB suffer this complication. While the data from the present study are close to those found by WILDER et al. [6] regarding the percentage of patients with $\mathrm{TB}$ suffering this type of 


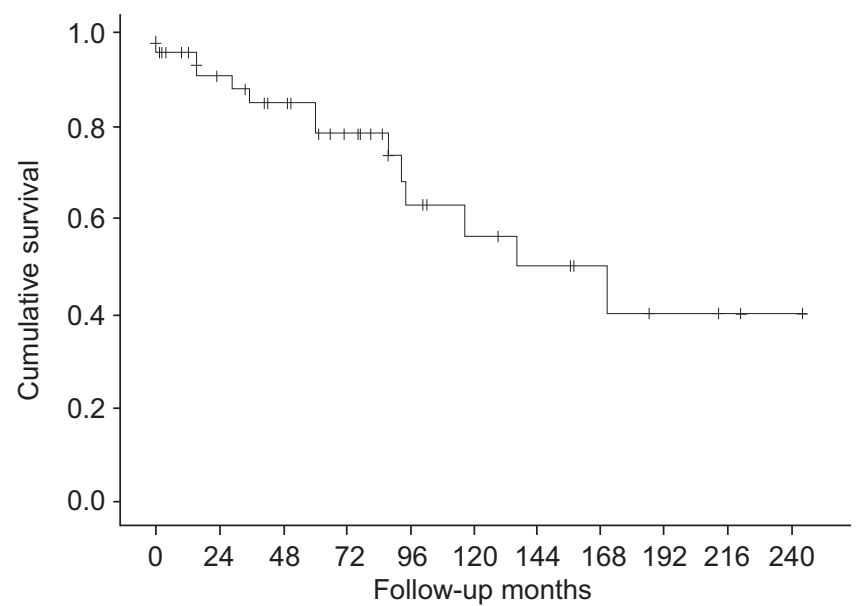

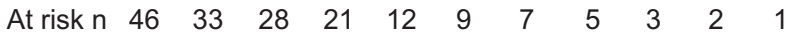

FIGURE 1. Actuarial Kaplan-Meier survival analysis of patients with pulmonary tuberculosis after pneumothorax.

complication, they are very low when the causes producing SSP are analysed. Later publications analysing the aetiology of SSP found that TB was decreasing progressively among causes $[9,10]$, which was linked to earlier diagnosis of TB cases and the possibility of cure with adequate drug treatment. Nevertheless, in a recently published study by Botianu [11], who retrospectively analysed all the cases of SSP at his institution between 1985 and 2004, a marked increase in TB as a cause of SSP during the period of study was found. Despite these discrepancies regarding whether $\mathrm{TB}$ is an increasingly or decreasingly frequent cause of SSP, it does seem to be accepted by most authors that TB is one of the most frequent causes of SSP $[2,12,13]$, with COPD being the most frequent [14].

In any case, as has been stated, there are very few studies that specifically analyse tuberculous SSP [11, 15-17] and to date, the clinical characteristics of this type of $\mathrm{SP}$, as well as its treatment, evolution, prognosis and survival, have not been sufficiently studied. In fact, a detailed analysis of the clinical and radiological presentation of these SSPs, such as possible factors associated with the recurrence of SSP and the survival of the patients, has yet to be reported. The present study provides new information that can be very useful for the future and should be tested by other authors.

The definition of SSP caused by TB is not a clear concept in the published studies addressing this issue. Many authors consider it in cases of active TB. In our study, we decided to include patients with TB antecedents, although they did not present activity at the time their SSP appeared. It is our opinion that SSP can occur at any moment of the disease, including at the stage of sequelae, because of the associated lung destruction that would be responsible for SSP, as was evident in our patients. In any case, many of the active TB cases probably also have TB sequelae, facilitating the possible SSP.

Radiological signs of destroyed lung are very frequent in this group of patients, reflected by the high percentage $(53.2 \%)$ found radiographically. Despite these data, the SSP treatment was not especially problematic and a resolution of episodes was obtained in most cases. It was only necessary to place more than one PD in $13 \%$ of cases; recurrences occurred in $23 \%$ and the total of patients that required surgery was $28 \%$. These figures can be considered acceptable, and are even lower than these in patients with primary SP [18] and for those recognised in general for SSP $[19,20]$. However, one cannot conclude that active TB will worsen the evolution of SSP, because there were no significant differences in this regard. The only inference that can differentiate the management of tuberculous SSP from that of primary SP is the number of days for which the PD was left in prior to indicating surgery for air leakage $(12.9 \pm 11.3$ days $)$, which is usually 5-7 days in primary SP [18]. This is indicative of a more conservative approach in tuberculous SSP. As for surgical interventions, all of these were performed using conventional procedures, with segmental resections and complementary procedures that were, in general, aimed at obtaining a correct pleural abrasion. This suggests that, in our experience, tuberculous SSP has a clinical behaviour that is not especially aggressive and that can be solved, in nearly all cases, with conventional surgical measures.

There are, however, a small number of cases in our series (4\%) with a fatal intrahospital evolution. All of those presented with poor general health and serious respiratory insufficiency that lead to death. As with previous cases, evolution during followup has shown mortality because of respiratory insufficiency, but without demonstrating significant differences in survival. It has been related only to the patients' age and the presence of HIV.

The present study analysed a group of patients affected with SSP and TB in detail, allowing a better characterisation of this type of patient. There are, however, some limitations to this study, which come from its retrospective character and small number of cases, although it has the largest number of cases that have been studied so far.

We conclude that SSP in patients with TB occurs especially in cases that demonstrate destroyed lung. PD is usually a good response, with only a small number of cases that require more than one PD and/or surgery, although it requires a high number of days on PD, a longer hospital stay and mortality in some cases of severe pulmonary affectation. Surgical treatment is standard, in general, and does not require major surgical manoeuvres. The survival of this group of patients is dictated more by age and the presence of HIV than by TB.

\section{STATEMENT OF INTEREST}

None declared.

\section{REFERENCES}

1 Noppen M, De Keukeleire T. Pneumothorax. Respiration 2008; 76: 121-127.

2 Blanco-Pérez J, Bordón J, Piñeiro-Amigo L, et al. Pneumothorax in active pulmonary tuberculosis: resurgence of an old complication? Respir Med 1998; 92: 1269-1272.

3 Beauchamp G, Ouellette D. Spontaneous pneumothorax and pneumomediastinum. In: Patterson GA, Cooper JD, Deslauriers J, et al., eds. Pearson's Thoracic and Esophageal Surgery. Philadelphia, Churchill Livingstone Elsevier, 2008; pp. 1094-1107.

4 Belmonte R, Crowe HM. Pneumothorax in patients with pulmonary tuberculosis. Clin Infect Dis 1995; 20: 1565.

5 Inh HJ, Hankins JR, Miller JE, et al. Pneumothorax associated with pulmonary tuberculosis. J Thorac Cardiovasc Surg 1972; 64: 211-219. 
6 Wilder RJ, Beacham EG, Ravitch MM. Spontaneous pneumothorax complicating cavitary tuberculosis. J Thorac Cardiovasc Surg 1962; 43: 561-573.

7 World Health Organization. Estimated Epidemiological Burden of TB, Update 2010. www.who.int/tb/country/data/download/en/ index.html Date last updated: 2010.

8 Caminero JA, Díaz F, Rodríguez de Castro F, et al. The epidemiology of tuberculosis in Gran Canaria, Canary Islands, 1988-92: efectiveness of control measures. Tuber Lung Dis 1995; 76: 387-393.

9 Kass EH. Infectious diseases and social changes. J Infect Dis 1971; 123: 100-115.

10 Wait M, Stresa A. Changing clinical spectrum of spontaneous pneumothorax. Am J Surg 1992; 164: 528-531.

11 Botianu PV. Spontaneous pneumothorax in tuberculosis. Chest 2004; 126: 894S.

12 Getz SB, Beasley WE. Spontaneous pneumothorax. Am J Surg 1983; 155: 823-827.

13 Tanaka $\mathrm{F}$, Itoh $\mathrm{M}$, Esaki $\mathrm{H}$, et al. Secondary spontaneous pneumothorax. Ann Thorac Surg 1993; 55: 372-376.
14 Zhang Y, Jiang G, Chen C, et al. Surgical management of secondary spontaneous pneumothorax in elderly patients with chronic obstructive pulmonary disease: retrospective study of 107 cases. J Thorac Cardiovasc Surg 2009; 57: 347-352.

15 Weissberg D, Refaely Y. Pneumothorax: experience with 1,199 patients. Chest 2000; 117: 1279-1285.

16 Mezghani S, Abdelghani A, Njima H, et al. Tuberculous pneumothorax. Retrospective study of 23 cases in Tunisia. Rev Pneumol Clin 2006; 62: 13-18.

17 Pis'mennyi AK, Fedorin IM, Muryshkin EV. [Specific features of spontaneous pneumothorax in patients with pulmonary tuberculosis.] Probl Tuberk 2002; 4: 25-27.

18 Freixinet J, Canalís E, Rodríguez de Castro F, et al. Surgical treatment of primary spontaneous pneumothorax with videoassisted thoracic surgery. Eur Respir J 1997; 10: 409-411.

19 Tschopp JM, Rami-Porta R, Noppen M, et al. Management of spontaneous pneumothorax. Eur Respir J 2006; 28: 637-650.

20 Rivas JJ, Jiménez M, Molins L, et al. Guidelines for the diagnosis and treatment of spontaneous pneumothorax. Arch Bronconeumol 2008; 44: 437-448. 